\title{
A PARTICIPAÇÃO SOCIOPOLÍTICA DO MOVIMENTO DOS TRABALHADORES RURAIS SEM TERRA (MST) EM CONSELHOS GESTORES: UMA ANÁLISE A PARTIR DOS PROCESSOS IDENTITÁRIOS
}

\author{
THE SOCIO-POLITICAL PARTICIPATION OF THE LANDLESS WORKERS' \\ MOVEMENT (MST) IN MANAGEMENT BOARDS: AN ANALYSIS BASED ON THE \\ IDENTITY PROCESSES
}

Claudia Kathyuscia Bispo de Jesus ${ }^{1}$

do: $10.21665 / 2318-3888 . v 5 n 10 p 239-261$

\section{RESUMO}

Esse trabalho discute a participação sociopolítica do Movimento dos Trabalhadores Rurais Sem Terra (MST) em conselhos gestores, do município de Nossa Senhora da Glória-Sergipe, a partir da análise dos processos identitários (Ennes; Marcon, 2014). Isto é, revelar os atores sociais, as disputas, os elementos morais e normativos, bem como os contextos sociais. Trata-se de uma pesquisa qualitativa, realizada através da observação direta, de entrevistas semiestruturadas e pesquisa documental que possibilitou a construção do corpus empírico, em que se pode concluir que a inserção participativa do MST em conselhos gestores corresponde a novos processos identitários dos integrantes do movimento sem terra que, por sua vez, estão alterando a dinâmica interna tanto dos conselhos quanto a do próprio movimento no que se refere à sua atuação política.

Palavras-chave: Conselhos Gestores. Movimentos Sociais. Participação Sociopolítica. Processos Identitários.

\footnotetext{
1 Doutoranda em Ciências Sociais pela Universidade Federal de Campina Grande (UFCG). E-mail: claudia_kathyuscia@hotmail.com.
} 


\section{ABSTRACT}

This paper discusses the socio-political participation of the Landless Workers' Movement (MST) in management councils, from the municipality of Nossa Senhora da GlóriaSergipe, based on the analysis of the identity processes (Ennes and Marcon, 2014). That is, to reveal the social actors, the disputes, the moral and normative elements, as well as the social contexts. It is a qualitative research carried out through the direct observation of semi-structured interviews and documentary research that enabled the construction of the empirical corpus, in which it can be concluded that the MST participatory insertion in management councils corresponds to new identity processes of the members of the landless movement which, in turn, are altering the internal dynamics of both the councils and the movement itself with regard to its political action.

Keywords: Management Councils. Social Movements. Social and Political Participation. Identity Processes. 


\section{Introdução}

A estrutura agrária brasileira, a permanência do poder das classes sociais rurais vinculadas aos grandes empreendimentos agropecuários, a pobreza e a negação de direitos sociais que marcaram, historicamente, a vida dos camponeses e demais trabalhadores(as) no campo foram elementos centrais definidores da formação, da identidade e da organização da sociedade brasileira e do seu meio rural. Nesse viés, a história do campesinato brasileiro é registrada pelas marcas de suas lutas na obtenção de um espaço próprio na economia e na sociedade, portanto, de processos sociais de resistência pelo direito de existir, em termos subjetivos, políticos, sociais, culturais e econômicos.

O Campesinato no Brasil sempre foi um setor "bloqueado historicamente", especialmente por conta da negação sistemática, em diversas localidades, do acesso dessa população a terra (WANDERLEY, 2009). Tais questões apresentaram-se - com particularidades, complementaridades ou oposições - nas abordagens de valiosos estudiosos da sociedade brasileira, ora enquanto componente importante dos debates existentes na nascente ciências sociais em nosso país, ora demarcando também as leituras de uma geração de estudiosos(as) da sociologia, principalmente, a sociologia rural - como: Bergamasco, 1996; Carvalho, 2005; lanni, 2004; Martins, 1981, 1983; Medeiros, 2010; Wanderley, 2003.

Esses estudos estavam inseridos em meio a um efervescente contexto sociopolítico da época, final da década de 60 , do século XX, pois era um cenário marcado pelo processo de internacionalização da indústria brasileira, bem como do avanço do capitalismo no campo, que impulsionaram o desenvolvimento da modernização do processo produtivo na agricultura. Desencadeou-se, enquanto reação a essa modernização excludente, uma forte organização dos trabalhadores rurais em vários municípios no país, que repercutiram em âmbito nacional por conta de seus atos políticos na década de 1950 e, principalmente nos primeiros anos de 1960 que antecederam à implantação do Regime Militar em 1964. A organização política dos camponeses contou com o apoio dos partidos políticos, sobretudo o Partido Comunista Brasileiro (PCB), e da Igreja Católica, os quais reunidos no I Congresso Nacional dos Lavradores e Trabalhadores Agrícolas, 
em 1961, formularam, pela primeira vez, uma proposta unitária de reforma agrária brasileira (MARTINS, 1981). Era uma síntese de suas interpretações política acerca da questão agrária no país, gerando repercussão na imprensa (rádio e jornal, na época).

A agenda política desses grupos campesinos expressava questões como: a) reforma agrária; b) livre direito à organização sociopolítica da classe trabalhadora rural; c) extensão de direitos trabalhistas para o campo, bem como previdenciários; d) fim do sistema de barracão e do cambão nos engenhos; e) políticas públicas ligadas ao desenvolvimento produtivo no campo, fundamentalmente para a pequena produção rural $^{2}$. O elenco de aspectos já referendados mostra como as áreas rurais estavam incólumes aos direitos de cidadania, particularmente, devido ao poder das elites agrárias em negá-los constantemente.

Esse período efervescente permitiu o acirramento dos conflitos no campo, sobretudo, com a criação e a ação das Ligas Camponesas ${ }^{3}$. Em meio à retomada das manifestações populares no período decisivo de encerramento do regime militar (1985), o movimento camponês ganhou (novo) impulso, com destaque para o Movimento dos Trabalhadores Rurais Sem Terra (MST).

As raízes do surgimento desse movimento foram determinadas por diversos fatores, dentre os principais: a) o aspecto socioeconômico das transformações que a agricultura brasileira sofreu na década de 70 do século passado; b) modernização e industrialização no campo; c) e a era da colonização da região Norte do país. Portanto, o nascimento do MST tem suas raízes nas condições objetivas do desenvolvimento da agricultura ${ }^{4}$ (STEDILE; FERNANDES, 2012).

\footnotetext{
${ }^{2}$ Ver: Andrade, 2005; Martins, 1981.

${ }^{3}$ As Ligas Camponesas foi um movimento camponês que teve seu início no ano de 1954 em Pernambuco e, posteriormente, na Paraíba, donde emergiram suas principais lideranças: João Pedro Teixeira, Elizabeth Teixeira, Júlia Santana, Francisco Julião e outros(as). As Ligas existiram até 1964, sendo eliminadas, assim como as demais organizações de camponeses e de trabalhadores rurais sindicalizados vinculados à esquerda. Tudo isso levou a um silenciamento da identidade política projetada a partir das ações e dos valores de mundo dos próprios homens do campo. Ainda sobre isso, ver Julião (1962).

${ }^{4}$ No próximo tópico darei continuidade às caracterizações do movimento sem terra.
} 
Vale ressaltar que a família rural assentada tenta garantir a reprodução social do grupo familiar e, consequentemente, a melhoria das condições de vida. São essas famílias e as dinâmicas existentes nos assentamentos que têm possibilitado em vários municípios formas de inclusão social antes precarizadas pela ausência da posse da terra. Ademais, são elas que passam a qualificar as políticas dos poderes públicos municipais, cobrando escolas, postos de saúde, melhorias de infraestrutura, entre outros (BERGAMASCO, 1996).

A partir desta referência aos Movimentos Sociais do Campo, em destaque o MST, e de suas frentes de atuações políticas ao longo do tempo, tivemos como questão de pesquisa: a participação sociopolítica do Movimento dos Trabalhadores Sem Terra (MST) em conselhos gestores do município de Nossa Senhora da Glória-Sergipe contribuiu (ou não) para a redefinição identitária dos integrantes do movimento?

Essa indagação foi o norte da minha de pesquisa de mestrado, que teve como objetivo apreender as razões pelas quais o MST, da regional de Nossa Senhora da Glória- SE, estava se inserindo na participação de conselhos gestores municipais e se essa participação correspondia a (novas) estratégias de atuação política por parte do movimento, bem como, se esse fato, representava mais uma composição identitária da cultura política do MST.

Para a realização do objetivo supracitado, recorremos à metodologia qualitativa para um estudo in loco, da qual fizemos uso da observação direta, de entrevistas semiestruturadas e pesquisa documental. As idas a campo ocorreram em dois momentos. O primeiro se deu pela viagem a Brasília, em fevereiro de 2014, para acompanhar o VICongresso Nacional do MST. E, o segundo momento ocorreu durante o período de outubro a dezembro de 2014, com as visitas a Nossa Senhora da Glória. Em suma, a realização dessa metodologia favoreceu a construção de um corpus empírico. Sendo que, ao todo, foram realizadas 12 (doze) entrevistas ${ }^{5}$; 1 (uma) observação direta e

\footnotetext{
${ }^{5}$ Três entrevistas aos dirigentes nacionais do MST, incluindo o representante de Sergipe que compunha a direção nacional; uma entrevista ao dirigente estadual e ao da regional de N. Sr ${ }^{\underline{a}}$ da Glória; duas entrevistas à representação governamental; cinco entrevistas com militantes do MST que eram conselheiros, ou que já foram conselheiros; uma entrevista com um representante da sociedade civil.
} 
pesquisa documental sobre o MST nacional/Sergipe e as resoluções pré-congressuais. Ademais, tivemos como aporte teórico a análise dos processos identitários - a partir de Ennes; Marcon, 2014 - que possibilitou a reflexão sobre a atuação do MST nos espaços deliberativos e os impactos disso na dimensão identitária do movimento.

Concluo, nesse viés, que a inserção participativa do MST em conselhos gestores está alterando a dinâmica interna tanto dos conselhos quanto a do próprio movimento no que se refere à sua atuação política; que, por sua vez, nos revela que não há uma constituição estática e universal da identidade do MST, mas sim uma multiplicidade decorrente de processos identitários que vão constituindo-se na ambivalência da luta e da dinâmica interna do próprio movimento sem terra.

Para facilitar o entendimento desse artigo, optamos por dividi-lo em dois momentos. No primeiro momento há uma breve apresentação sobre o MST, destacando suas características de participação; e, no segundo momento, a discussão sobre a inserção do MST em conselhos gestores, bem como os dilemas e as experiências participativas. Desse modo, especificaremos a participação do MST nesses arranjos institucionais como configuração expressiva de processos identitários, revelando os atores sociais, os motivos de disputa, os seus dilemas; seguindo com os elementos morais e normativos que orientaram as relações e as ações dos mesmos nesses espaços.

\section{O Movimento dos Trabalhadores Rurais Sem Terra (MST)}

A gênese do MST ocorreu mediante um contexto de modificações no campo brasileiro, na década de 1970, das quais podemos destacar quatro processos: a) o aspecto socioeconômico das transformações na agricultura brasileira; b) a modernização no campo, com a entrada da mecanização, que impulsionou o êxodo rural; c) o processo de industrialização, afinal, estava sob o efeito do "milagre econômico"; d) e a colonização na região Norte, especialmente em Rondônia, Pará e Mato Grosso (STEDILE; FERNANDES, 2012). 
Esses quatro processos, mencionados acima, corresponderam à base social que gerou o MST. Nessa perspectiva, percebemos, claramente, que o MST surgiu na região Centro Sul do Brasil, no período de 1984-1985. O movimento só teve, de fato, contorno e repercussão nacional a partir dos anos 90 , do século $\mathrm{XX}$, devido às vitórias e emblemas dos processos de ocupações de terra da época, a exemplo da ocupação na fazenda Macali, localizada no Rio Grande do Sul (TURATTI, 2005).

É importante destacar que para além dessas condições objetivas diante das metamorfoses no campo brasileiro, o MST também possui nas suas raízes a influência das Ligas Camponesas e, principalmente, do trabalho pastoral das igrejas Católicas e Luterana (STEDILE; FERNANDES, 2012). A forte presença da igreja (progressista) como impulsionadora no surgimento do MST foi decorrente da ideologia da Comissão Pastoral da Terra (CPT) 6.

O MST apresenta características de natureza importantes. A primeira diz respeito à inclusão de todos os membros da família, pois, sua base é familiar ${ }^{7}$. Uma vez que, é no âmbito familiar que se discute e organiza-se a inserção produtiva, laboral, social e moral de seus integrantes; sendo também em função desse referencial que são estabelecidas as estratégias individuais e coletivas, que visam garantir a reprodução social do grupo familiar. Dessa maneira, a família rural representa o trabalho (o predomínio da agricultura como base familiar), a segurança (garantia de futuro) e a conservação dos valores, tradições e costumes ${ }^{8}$.

\footnotetext{
${ }^{6}$ Surgiu em 1975 em Goiânia, vinculado à Conferência Nacional dos Bispos do Brasil (CNBB) cuja perspectiva doutrinária foi o da Teologia da Libertação-prática religiosa voltada para a realidade social. Para um maior conhecimento dessa corrente cristã, ver: Boff (2010). Sobre a mediação entre a Teologia da Libertação e os movimentos sociais no campo, ler: lokoi (1996).

7 De um modo geral, podemos dizer que os inúmeros pesquisadores das ciências sociais, que direcionaram seus esforços de pesquisas para o tema das questões rurais e agrárias, a exemplos de Bergamasco et al (2003), Loera (2006) e Martins (2003), afirmam que o sujeito principalmente da reforma agrária no país tem um núcleo basicamente familiar, de família extensa e é a partir dela e de suas experiências cotidianas que podemos perceber - do ponto de vista sociológico - as próprias mudanças e/ou continuidades de antigas situações de vida no campo.

${ }^{8}$ Bergamasco et al. (2003), Leite (2004) e Medeiros (1994).
} 
Outra característica presente no MST é a sua articulação com o movimento sindical. Isso porque, o movimento compreende que os agricultores assentados rurais precisam se vincular aos sindicatos dos trabalhadores rurais como via de acesso a benefícios voltados para a sua produção. No entanto, da mesma forma em que o MST estimula a filiação aos sindicatos rurais, o próprio movimento faz suas ressalvas a isso:

Aprendemos ainda que a luta pela terra não pode se restringir ao seu caráter corporativo, ao elemento sindical. Ela tem de ir mais longe. Se uma família lutar apenas pelo seu pedaço de terra e perder o vínculo com uma organização maior, a luta pela terra não terá futuro. É justamente essa organização maior que fará que a luta pela terra se transforme na luta pela reforma agrária. Aí, já é um estágio superior da luta corporativa. É agregado à luta pela terra o elemento político (STEDILE \& FERNANDES, 2012, p. 37).

É esse elemento político que corresponde ao terceiro elemento característico do MST. Nesse sentido destacamos que, segundo Stedile; Fernandes (2012, p.33), "na essência, o MST nasceu como um movimento camponês, que tinha como bandeira as três reivindicações prioritárias: terra; reforma agrária e mudanças gerais na sociedade".

\title{
1.1 A participação para o Movimento dos Trabalhadores Sem Terra
}

Por "participação" o Movimento dos Trabalhadores Rurais Sem Terra entende:

\begin{abstract}
Participar quer dizer fazer parte, ter o reconhecimento da importância de compor algo maior do que somos individualmente. Fazer parte, no caso do MST, é assumir uma nova identidade, como o objeto que se transforma em símbolo [!]. É emprestar- se para adquirir outra natureza. Deixar- se comparar com outro símbolo, neste caso, outro ser social que faz parte da mesma sociedade em que vivemos (BOGO, 2002, p. 153)
\end{abstract}

Nesse viés, percebe-se que para o MST a participação na luta pela terra significa não somente a luta pela distribuição de terra, mas também construir (novas) relações de poder, de direitos. Tais (novas) relações sob uma concepção de diferentes relações sociais de uma sociedade.

Além disso, participação para o MST corresponde a um dos elementos da estrutura organizativa do movimento. Pois, segundo o próprio movimento, "a participação de 
todas as pessoas que estão nas áreas de reforma agrária confronta-se com os limites que estabelece a estrutura organizativa" (BOGO, 2002, p.159). Isso porque, recorrendo aos documentos do movimento, bem como ao material bibliográfico sobre a organização do MST, encontramos os seguintes princípios organizativos: a) direção coletiva; b) divisão de tarefas; c) disciplina; d) estudo; e) vínculo com a base (FERNANDES; STEDILE, 2012). Todos esses princípios organizativos do movimento citados, aqui, estão relacionados à sua própria concepção de participação política, afinal, "pode-se dizer que a participação tende para a organização e que a organização facilita e canaliza a participação. De fato, a organização não é um fim em si mesmo, mas uma condição necessária para a participação transformadora" (BORDENAVE, 1994, p. 67).

Vale destacar que, a Mística, um dos elementos constituintes da formação do MST, cumpre um papel crucial no estímulo à participação dos integrantes do movimento, uma vez que esta prática social tem como desafio fazer com que as pessoas se sintam bem em participar da luta. Dessa forma, segundo o MST, "este é um dos grandes desafios que temos internamente, em que a mística da participação e da valorização deverá despertar o interesse e desconstruir a ideologia dominante e construir a ideologia libertária" (BOGO, 2002, p.158).

Além dos elementos organizativos como canalizadores da participação (fazer-se parte) há também outras formas de expressões de participação, que percebemos no decorrer da análise dos documentos congressuais ao VI- Congresso do Movimento dos Trabalhadores Rurais Sem Terra (MST) ${ }^{9}$, das quais destacamos:

- Garantir a participação igualitária das mulheres que vivem no campo em todas as atividades, em especial no acesso a terra, na produção e gestão, buscando superar a opressão histórica imposta às mulheres;

- A reorganização da produção agrícola brasileira deve vir acompanhada por um novo sistema de planejamento e tecnologias orientadas pelo enfoque ecológico e participativo, adequando-se à reforma agrária, as unidades camponesas de produção, buscando aumento da produtividade em equilíbrio com o meio ambiente;

\footnotetext{
${ }^{9}(\mathrm{MST}, 2013)$.
} 
- Pesquisa participativa: com a geração de tecnologias apropriadas às distintas realidades locais e regionais, com protagonismo dos camponeses e das camponesas;

- Desenvolver uma metodologia participativa em que o sistema financeiro público vá até os pequenos agricultores de forma desburocratizada e estimulando formas cooperadas, combatendo oportunismos e desvios;

- As escolas de assentamentos e de comunidades devem ter uma gestão democrática com a participação da comunidade, de educadores e educando;

- É necessário organizar, massificar e ampliar a participação popular nas lutas e mobilizações, de forma permanente. As mudanças necessárias somente serão realizáveis com ampla participação popular, antes e durante a aplicação do programa;

- O Estado deve mudar sua natureza atual. Deverá ser gerido democraticamente, com ampla participação das massas e buscando o bem comum;

A partir dos pontos apresentados, percebe-se que a participação para o MST vai além do âmbito organizativo. Ela apresenta-se sobre várias formas e nuances. Dessa maneira, aparece a participação enquanto combate às desigualdades de gênero; no seu modelo tecnológico de produção agrícola; nas suas práticas para o desenvolvimento da infraestrutura social; e, por fim, no seu modo de mobilização. Dessa forma, todas estas formas exibidas são identificadas, para o MST, como condição necessária para a implantação do Programa de Reforma Agrária Popular.

Nota-se também, no decorrer da análise dos documentos do MST, que não há um direcionamento explícito sobre a inserção participativa em conselhos gestores, mas sim:

O MST deverá inserir-se socialmente nas organizações sociais, instituições etc. de disputa pelos espaços de influência, não para reproduzir a mesmice, mas como forma de alavancar alternativas de poder popular e angariar apoios para seu projeto de um outro mundo rural, que não o do agronegócio, com todas as suas mazelas... Porém, deverá fazer isto não como um comportamento voluntarista da militância, mas com projeções e intencionalidade, com diretrizes, metas projeto e etc. Com um comportamento de organização política e não só de caráter orientativo, generalizante, voluntarista e frouxo (CEZIMBRA; SANTOS; MARTINS, 2013, grifo nosso).

Para tanto, esta orientação pode possibilitar a abertura da inserção de integrantes do MST em conselhos gestores, conforme as ressaltas já apresentadas acima. 


\section{O dilema da participação do MST em Conselhos Gestores}

O MST estimula a participação de seus militantes para disputa por espaços sociais e, ao mesmo tempo, sinaliza as "limitações" diante de tal participação: "Os Conselhos Nacionais organizados para decidir e planejar as políticas públicas são instituições importantíssimas. Mas existe tensão nestes espaços, pois estão dentro da conformação da ordem" (ROSSETO; RIBEIRO, 2013). Nota-se o reconhecimento, por parte do MST, dos entraves frente à participação em conselhos. E isso corresponde a um dos principais argumentos desfavoráveis à inserção por parte de alguns militantes, como veremos nas falas dos entrevistados.

Durante a pesquisa de campo, em Nossa Senhora da Glória, foram identificados os conselhos existentes $^{10}$, onde pudemos perceber, de início, a participação da sociedade civil na composição dos conselhos. Em alguns conselhos, era perceptível o esforço dos representantes da sociedade civil em querer participar organicamente na divulgação do acesso aos direitos sociais; em fazerem-se presentes às reuniões; enfim, em tentar realizar o papel de um conselheiro no controle social. No aspecto da autonomia dos conselhos gestores, identificamos certo antagonismo entre as falas dos governamentais e os nãos governamentais. Uma vez que, os representantes do gestor público, durante as entrevistas, não demonstraram ser tão "realistas", diante das dificuldades do conselho, como os representantes da sociedade civil (que no caso desta pesquisa foi à representação do MST). Nesse sentido, destacaremos a seguir as principais experiências vividas pelos militantes do MST na condição de conselheiros.

A primeira entrevista realizada na pesquisa foi feita com o dirigente Estadual e da Regional de $\mathrm{Nsr}^{\underline{a}}$ da Glória para compreender os motivos da participação de alguns integrantes do MST-Glória nos conselhos municipais. Ao coletar tal informação, fomos

\footnotetext{
10 Ao todo, foram encontrados 9 (nove) conselhos municipais, além do Conselho Tutelar. A saber: Conselho Municipal de Acompanhamento e Controle Social do FUNDEB; Conselho Municipal de Alimentação Escolar (COMAE); Conselho Municipal de Assistencia Social (CMAS); Conselho Municipal de Desenvolvimento Sustentável (CMDS); Conselho Municipal de Saúde (CMS); Conselho Municipal de Segurança Alimentar e Nutricional (COMSEA); Conselho Municipal do Direito da Criança e do Adolescente (COMDCA); Conselho Municipal dos Direitos da Mulher (CMDM); Conselho Municipal dos Direitos e Proteção do Idoso (KATHYUSCIA, 20015).
} 
surpreendidos com o relato do entrevistado, que nos revelou que outra organização social do campo, da qual fazia parte antes de integrar ao MST, já havia tido a experiência participativa em conselhos. É o que podemos constatar na fala do entrevistado:

Eu já vim de outra organização, o sindicato rural, e eu já participava no meu município de vários conselhos. Já participei de quase todos os conselhos municipais. E ao me integrar ao movimento Sem Terra vi que o movimento num era muito inserido nos conselhos e achei que isso não era correto, que as pessoas tinham que se inserir. Que o MST enquanto um movimento de massas tinha que ocupar todos os espaços da sociedade e aí a gente foi fazendo essa discussão e não só aqui na micro, Glória, mas em toda a região e em todo o estado. E aí tem conselheiro do movimento participando e achando que o que nós quer é ocupar todos os espaços dos conselhos e de outras coisas (DIR. ESTADUAL, 2014).

Isso nos revela que a participação de movimentos sociais do campo em conselhos gestores não é uma novidade "inaugurada" pelo MST. Quando na verdade, segundo Ribeiro; Santana (2002), a participação dos agricultores organizados em conselhos ocorre desde os primeiros espaços deliberativos e participativos da sociedade civil, voltando-se a programas e políticas para a zona rural.

No que se refere à indagação sobre a participação do MST em conselhos corresponder(ou não) a uma nova estratégia de atuação política por parte do movimento, constatamos que a participação de militantes do MST, nesses arranjos institucionais, é uma tentativa de obtenção de recursos públicos para as famílias assentadas, haja vista que após o processo de conquista da terra o movimento inicia outra luta - simbólica e institucional - para a garantia, a consolidação e a manutenção dos assentamentos rurais de reforma agrária. Sobre essa luta institucional travada pelo MST, destacamos a tese de Gismário Nobre (2008) que analisou a relação entre o MST e o Estado destacando a relação contraditória entre a autonomia do movimento enquanto sujeito social e a institucionalidade democrática. Destarte,

É sabido que os primeiros dez anos de implantação da política de assentamentos a ação do Estado caracterizou-se por ser pontual e sempre sob a pressão dos movimentos sociais, não apenas na questão da desapropriação da terra, mas também com relação às demais ações complementares indispensáveis à consolidação dos assentamentos (NOBRE, 2008, p. 137).

Sendo assim, compreendem-se as justificativas dos militantes do MST, sobretudo os do município de Nossa Sra Glória, em relação à sua atuação nos conselhos municipais. Como podemos observar abaixo: 


\section{É nos conselhos que onde o assentado vai descobrir algumas políticas públicas pra poder levar pro seu próprio assentamento e ele vai pegar um conhecimento e além de ter essas políticas que discutidas e distribuídas pelo conselho. E aí o conselho vai ser pra ele uma maneira dele aprender mais e tá envolvido na discussão de seus próprios problemas e encaminhando (DIR. ESTADUAL, 2014, grifo nosso).}

Sobre a realidade das condições dos assentamentos rurais no Brasil, destaco:

Com relação às pessoas que já foram assentadas, um dos problemas enfrentados é a falta de recursos suficientes e a liberação dos existentes. Na visão do MST, a falta de planejamento na distribuição de recursos, levando em conta as peculiaridades de cada região e a época de plantio de cada tipo de grão, compromete a gestão dos recursos e o sucesso das atividades agrícolas dos assentamentos. Atualmente há uma tendência a desburocratizar os financiamentos (SOARES, 2004, p.24).

Portanto, uma das razões que nos ajuda a compreender a inserção do MST nos espaços deliberativos de políticas públicas, é a busca por acesso a benefícios para as famílias rurais assentadas, uma vez que a conquista da terra não assegura a obtenção de outros benefícios sociais.

\subsection{Assentado rural- conselheiro gestor: uma redefinição identitária}

Ao término da análise da participação sociopolítica do MST, é importante analisar em que medida essa experiência participativa do militante do MST-Glória nos conselhos gestores, corroborou novos processos identitários do movimento a partir de outras dimensões participativas, que os militantes estão inseridos, e de confrontados com novas situações como, por exemplo, outros atores sociais, novas disputas, normas impostas e contextos sociais diferentes.

A considerar que nas ciências sociais são vastas as produções teóricas que abordam o tema das identidades (e processos identitários), e que a intenção desta temática é apenas de subsídio de análise, trataremos apenas de modo sumário. Sendo assim, utilizaremos a abordagem de processos identitários seguido pelas contribuições de Ennes; Marcon $(2014)^{11}$, cujos autores abordam os processos identitários mediante 4 parâmetros: a) os

11 As principais categorias envolvidas nessa construção de pensamento sobre o entendimento dos processos identitários aproximam-se da Interculturalidade (E. Canclini); da Ambivalência (Z. Bauman); do Estigma (E. Goffman) e da conversão do estigma e emblema do Pierre Bourdieu. 
atores sociais; b) os motivos de disputas; c) os elementos morais e normativos e d) os contextos sociais.

O primeiro parâmetro para pensar os processos identitários é o ator social, ou melhor, os atores sociais articulados a grupos. Para tanto, o ator social tratado neste trabalho refere-se ao MST. Ao passo em que o movimento se inseriu em conselhos gestores ou outro campo de atuação institucional, precisou desenhar demarcações de diferenças entre os outros atores sociais que já existiam nos conselhos. Assim, acredita-se que o diferencial, por parte do MST, seja a sua bagagem de formação e atuação política, ou usando de um termo bourdiesiano, de seu capital simbólico ${ }^{12}$ no que se refere à experiência em instâncias deliberativas presente no interior do movimento ${ }^{13}$. Como foi o caso de um dos entrevistados, que além de ser conselheiro do Centro Dom José Brandão de Castro ${ }^{14}$ e da Rede de agricultura do Alto Sertão Sergipano é integrante da setorial de Direitos Humanos.

O segundo parâmetro centra-se nos motivos da disputa. Essa disputa decorre tanto do processo de diferenciação como também das concorrências internas. A partir do pressuposto de campo político - como espaços de relações objetivas e de lutas caracterizadas pela heterogeneidade de disputas - podemos compreender que as disputas entre os diferentes atores sociais são travadas no campo político, isto é, "no campo de forças e como campo das lutas que têm em vista transformar a relação de

\footnotetext{
12 Entende-se como representação do que você constrói dentro de um espaço social (BOURDIEU, 2009).

${ }^{13}$ O MST, no aspecto organizacional, apresenta organizações internas através de setoriais temáticas, que são: setor de formação; de educação; de produção; de finanças; projetos; comunicação; relações internacionais; de gênero e de direitos humanos, além das secretarias nacional e estaduais (MORISSAWA, 2001).

${ }^{14}$ Centro de Assessoria e Serviço aos/ às Trabalhadores/as da Terra- Dom José Brandão de Castro- CDJBC A missão institucional do CDJBC é contribuir para o fortalecimento das formas de organização e qualificação dos/as trabalhadores/as rurais sergipanos/as na luta pela superação da exclusão social. Assim voltado para crianças, jovens, mulheres e homens do campo, acreditando no protagonismo destes sujeitos para a construção de políticas públicas que assegurem a cidadania das comunidades rurais. O CDJBC foi fundado em 11 de junho de 1995 por trabalhadores/ as rurais e pessoas envolvidas na luta por uma cidadania e direitos no campo, tendo como objetivo promover a melhoria da qualidade de vida no campo dos sergipanos. O CDJBC tem em D. José Brandão de Castro, primeiro bispo da diocese de Propriá- SE, o seu referencial de mística e compromisso em defesa da vida e contra toda forma de exploração dos/as trabalhadores/as do campo. A organização tem o reconhecimento de utilidade pública municipal (2002), estadual (1997) e federal (2003). Está escrita desde 2002 no Conselho Nacional de Assistência Social (CDJBC, 2015).
} 
forças que confere a este campo a sua estrutura em dado momento" (BOURDIEU, 2011 p. 163-164). Podemos destacar como exemplo de disputa o processo eleitoral para participar da nova gestão do conselho, como foi observado em alguns dos relatos dos assentados entrevistados.

No inicio da gestão [em 2013, no Conselho Estadual de Articulação do SemiÁrido] se nós não tivesse um número mínimo de militante nosso fica difícil de nós entrar nos conselhos. Então, nós ficamos atentos com as eleições de conselhos pra está presente. Porque muitas entidades faz de tudo possível pra o MST não participar. Então nós temos que ficar muito atento pra poder nunca deixar de ter alguém nosso dentro dos conselhos (MST- CONSELHEIRO3, 2014).

De tal modo, percebe-se a heterogeneidade de disputas diante desse campo político, pois ocorre tanto com a relação entre a representação governamental como a da sociedade civil.

As normas e os princípios sociais são cruciais para o regulamento das relações sociais nos processos identitários e estão elencados como o terceiro parâmetro dos processos identitários, isso por que:

As normas que norteiam as relações sociais podem ser expressas na forma de costumes, tradições, leis ou discursos. Neste caso, a questão do poder reaparece numa condição em que as práticas e normas se reproduzem e estão mutuamente implicadas. Aqui, não estamos considerando que os atores sociais simplesmente se adéquam a regras. Ao contrário, partimos do pressuposto de que as normas e os discursos bem como as instituições que as sustentam, são produzidas 'nas' e a partir 'das' relações de poder (ENNES; MARCON, 2014, p.17).

Nesse bojo, podemos considerar o modo de agir, bem como as normas oficiais presente nos conselhos e que os integrantes do MST tiveram que interiorizar tais princípios sociais nesse (novo) campo de atuação. A ideia de interiorização trazida aqui baseia se com a noção de habitus de Pierre Bourdieu (2009), ou seja, houve por parte do assentadoconselheiro um processo de interiorização da exterioridade e exteriorização da interioridade. Portanto, a partir da inserção desse ator social nos conselhos ocorreu o momento de absorver a dinâmica interna dos conselhos já "normatizada" para, a partir daí, colocar para fora, reagir a isso através do reconhecimento e impulsiona-o a se inserir no jogo de interesse, isto é, "estar em", participar desse jogo de disputa (BOURDIEU, 1996). 
Essa consideração do habitus está relacionada ao entendimento de campo. Afinal, não dá pra pensar em campo sem discutir a noção de habitus, isto é, a relação de interiorização da exterioridade e a exteriorização da interioridade que perpassa no campo. (BOURDIEU, 2009)

O quarto parâmetro é o do contexto social. Este é notório como significante para o entendimento da inserção do MST nos conselhos. Na medida em que foi destacado no decorrer do texto que o período em que ocorreu um reordenamento na gerência das políticas públicas por parte do governo federal, esta descentralização tornou o conselho como principal canal de acesso às políticas sociais. E considerando a dificuldade de entrada aos recursos públicos por parte das famílias rurais assentadas, pós a conquista da terra, desencadeou no movimento a necessidade de traçar uma nova estratégia de atuação política frente ao novo cenário.

É importante destacar que, além desses quatros parâmetros traçados aqui como elementos significantes no processo de redefinição identitária, o elemento identificação (SANTOS, 2010) ficava muito evidenciado nos relatos dos entrevistados. Pois, das perguntas semidirigidas, algumas eram direcionadas as próprias percepções diante da sua nova condição de conselheiro. E as respostas transmitiam certo domínio sobre o seu papel de conselheiro e, principalmente, o reconhecimento das debilidades que os conselhos se encontram.

O negativo é que a maioria dos conselheiros eles ainda não são conscientes. Não tô citando aqui os conselheiros do movimento, pois aqui eles sempre tiveram instrução. Mas na maioria, eles são aqueles conselheiros que não debate, que não questionam porque eles não têm bem o conhecimento (MSTCONSELHEIRO5, 2014).

Em suma, esses elementos destacados são importantes para o entendimento dos processos identitários que o MST iniciou e vem vivenciando, na condição de assentadoconselheiro, mediante a sua nova socialização, neste caso em conselhos gestores. Embora tal socialização, compreendida como um processo de construção de identidades (DUBAR, 2005), desencadeasse em novas sociabilidades para esses atores sociais, é necessário destacar que o pertencimento, a identificação com o MST ainda se faz 
presente nos discursos dos militantes, daí se justifica a compreensão desses processos identitários mesmo diante dessa nova dinâmica de experiência sociopolítica.

\begin{abstract}
Reafirmo a minha referência em nossa formação político-ideológico e a compreensão de que não podemos nos furtar em contribuir nos mais diversos espaços, pois atingimos um nível organizacional enquanto movimento social camponês que nos imprime essa responsabilidade (...) Como militante do MST, vejo a participação nos conselhos como a oportunidade de fazer a interlocução dos debates e das ações das políticas públicas com a ação e a mobilização social. Assim, buscar sistematizar as demandas do movimento para debatê-las e construir propostas no que compete às atribuições dos respectivos conselhos, mas também levar ao movimento o quê existe e como se estrutura as políticas públicas (MST- CONSELHEIRO5, 2014).
\end{abstract}

Portanto, nota-se o reconhecimento da importância de participação nos conselhos. Há identificação perante essa (nova) atuação que é (e foi gerada) a partir da inserção nesse espaço social de disputa, de normas e de regulação e, que mesmo assim este ator social, o MST, produz suas diferenciações, seja no tocante à formação e instrução perante a sua base que atua nos conselhos, caracterizando-se como o militante político que atua nos conselhos, seja pela afirmação e demarcação de configurações frente aos outros atores sociais contidos nos conselhos.

\title{
Considerações Finais
}

A tentativa de análise da participação sociopolítica do MST em conselhos gestores revelou a necessidade de uma extensão da análise, isto por considerar que esse fenômeno ainda é recente, no tocante à análise sociológica. Valeria um aprofundamento dessa realidade operacional frente ao engajamento do MST nos conselhos.

Considera-se que a recriação das práticas participativas do MST é resultante também das transformações ocorridas no campo brasileiro, onde desencadearam nos movimentos sociais do campo novas formas de resistência e estratégias de luta para a garantia de sua permanência frente à avalanche de consequências doravante da expansão do capitalismo no meio rural. 
O cenário de transformações do mundo rural, nas últimas décadas, implicou a heterogeneidade das forças sociais presente no campo, o que gerou um novo olhar sobre as interpretações dos movimentos sociais rurais. Com isso, outras abordagens surgem, para além da clássica marxista em que a explicação se dava pelas determinações econômicas estruturais das ações coletivas, para explicar a pluralidade das novas problematizações que emergiam a partir do final da década de 80 .

Dessa forma, as novas abordagens sobre os movimentos sociais (rurais) buscam compreender, não somente o campesinato em si, mas também a questão da cultura e, principalmente, as relações sociais do cotidiano e dos processos identitários específicos de cada movimento que emergem nos embates, aproximações e da contingência destas relações.

Os motivos e finalidades da inserção participativa do MST no mecanismo institucional, que é o conselho gestor, expostos aqui, revelam que a justificativa se dá pelas precárias condições sociais e econômicas em que se encontram os assentamentos rurais após a conquista da terra. Ademais, identificou-se no conselho o canal de acesso às políticas públicas para beneficiamento das famílias rurais assentadas. Uma vez que, tais políticas são fomentadas e acessadas pelas instâncias deliberativas dos conselhos.

A partir da compreensão da inserção do MST nos conselhos gestores, pode-se analisar como esta participação possibilitou alterações na dinâmica interna da própria organização. Essa alteração foi revelada através dessa nova atuação política que desencadeou em um processo de aglutinação de outro elemento identitário na cultura política do MST. Estes, até então, tinham como principal forma de atuação política o confronto direto com o Estado na luta pela terra, e, agora, estão se inserindo em um novo cenário de atuação, onde a disputa, as normas, o conflito e a contradição são elementos constituintes dos espaços de participação e deliberação pública.

O primeiro destaque que fazemos das análises elaboradas no decorrer deste trabalho é sobre a potencialidade da participação do MST nos conselhos. Isto se refere, com base nas entrevistas feitas e na observação direta, ao impulsionamento que este movimento vem dando à retomada da participação da sociedade civil organizada nos conselhos. 
Conselhos estes, resultantes do protagonismo da própria sociedade civil em querer participar das decisões públicas e orçamentárias do Estado.

Além disso, pode-se pensar que esta potencialidade, destacada aqui, marca outro ponto de análise sobre conselhos ou qualquer espaço de participação e deliberação que é a (nova) inserção de atores políticos nos arranjos institucionais, dos quais se diferenciam dos "antigos" atores sociais que já compunham os conselhos desde seu surgimento, como, por exemplo, os representantes de associação de bairros.

Estes ditos atores políticos apresentam características diferenciadoras, que chamaríamos a atenção para uma: a formação política pedagógica para a atuação deles nos espaços participativos e de decisão. E o MST traz, desde os seus princípios políticos, a importância da formação de quadros. Formação esta que muito já se foi estudada, principalmente no campo da educação, para compreender o processo formativoeducativo do movimento e como isso se repercute na formação e na socialização dos integrantes do movimento. Ademais, no decorrer das entrevistas, foi destacado esse momento de formação como direcionamento na atuação do assentado que é conselheiro.

Além de algumas potencialidades aludidas acima podem-se destacar também os limites da participação do MST nos conselhos gestores. A limitação foi notória, principalmente com os depoimentos dos entrevistados da direção nacional do movimento, ao reconhecer os riscos diante da atuação dos conselhos. Isso porque, é perceptível para o movimento os entraves que o conselho pode apresentar mediante a sua relação com o poder público.

Outro limite destacado pelos próprios informantes do movimento é que a inserção e a participação do MST em arranjos institucionais não é a sua via principal de atuação política. Ainda continua a ser o enfrentamento e o confronto com o Estado através, principalmente, das ocupações de terra. Portanto, a participação do MST em conselhos gestores é justificada por questões conjunturais, onde foi buscar uma estratégia de angariação de recursos públicos para a manutenção e a garantia de permanência dos 
assentamentos rurais diante das precárias condições que se encontram pós a obtenção da posse da terra.

Por fim, considero que a inserção de militantes do MST em conselhos possibilitou novos processos identitários mediante a socialização estabelecida nesse (novo) campo, onde as trocas de saberes e, sobretudo, as disputas contribuíram para a incorporação de elementos exteriores à dinâmica interna já vivida no movimento e, assim, ressignificar a sua atuação política, que por sua vez é um espaço de institucionalização da participação. E, portanto, coloca na ordem do dia reivindicações de garantia de permanência desses sujeitos na viabilização de sua reprodução social.

\section{Referências}

ANDRADE, Manuel Correa de. A terra e o homem no Nordeste: contribuições ao estudo da questão agrária no Nordeste. São Paulo: Cortez, 2005.

BERGAMASCO, Sônia Maria Pessoa Pereira. O que são assentamentos rurais. São Paulo: Brasiliense, 1996.

BERGAMASCO, Sônia et al. (orgs.). Dinâmicas familiar, produtiva e cultural nos assentamentos rurais de São Paulo. Campinas: Feagri- UNICAMP; Araraquara: Uniara; São Paulo: INCRA, 2003.

BOFF, Leonardo. Como fazer Teologia da Libertação. 10ed. Petrópolis, RJ: Vozes, 2010.

BOGO, Ademar. O vigor da mística. Caderno de Cultura do MST. № 02, Novembro, 2002.

BORDENAVE, Juan E. Diaz. O que é participação? São Paulo: Brasiliense, 1994.

BOURDIEU, Pierre. O senso prático. Petrópolis- RJ: Vozes, 2009.

. Razões Práticas: sobre a teoria da ação. Campinas: Papirus, 1996.

O poder simbólico. 15º edição, Rio de Janeiro, Bertrand Brasil, 2011.

BRASIL, Ministério da Previdência Social. Diálogo social e gestão participativa. Brasília: MPS, 2003. 
BRASIL. MDA. II Plano Nacional de Reforma Agrária. Brasília: MDA, Nov, 2003.

CARVALHO, Horácio Martins de. O campesinato no século XXI: possibilidades e condicionantes do desenvolvimento do campesinato no Brasil. Petrópolis, RJ: Vozes, 2005.

CDJBC. Centro de Assessoria e Serviço aos/ às Trabalhadores/as da Terra- Dom José Brandão de Castro.Quem somos/ nossa missão. Disponível em: http://www.cdjbc.org.br/ler.asp?id=2\&titulo=conteudo\&onRollOver=\%5Btype+Functio

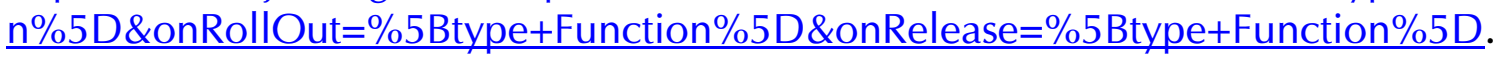

Acesso: 18 de jan. 2015.

CEZIMBRA, Elemar; SANTOS, Marina; MARTINS, Horácio. O Estado burguês e os governos. In: MST. Subsídios para debate de temas estruturais da sociedade brasileira e os desafios para uma reforma agrária popular. Caderno de Debates № 01- preparação para o VI- Congresso Nacional. Jun. 2013.

DUBAR, Claude. A socialização: construção das identidades sociais e profissionais. São Paulo: Martins Fontes, 2005.

ENNES, Marcelo; MARCON, Frank. Das identidades aos processos identitários: repensando conexões entre cultura e poder. Revista Sociologias, Porto Alegre, ano 16, no. 35, jan/abr 2014, p. 274-305. Disponível em: http://www.scielo.br/pdf/soc/v16n35/a10v16n35.pdf. Acesso em: jul, 2016.

FERNANDES, Bernardo Mançano. MST: movimento dos trabalhadores rurais sem-terra, formação e territorializacão em São Paulo. São Paulo: HUCITEC, 1996.

. Gênese e desenvolvimento do MST. Cadernos de Formação, no 30. São Paulo: MST, 1998.

IANNI, Octavio. Origens Agrárias do Estado Brasileiro. São Paulo: Brasilense, 2004.

IBGE. Censo Demográfico 2000 e Pesquisa de Orçamentos Familiares- POF 2002/ 2003.

Disponível em:

http://www.cidades.ibge.gov.br/xtras/temas.php?lang=\&codmun=280450\&idtema=19\& search=sergipelnossa-senhora-da-glorialmapa-de-pobreza-e-desigualdade-municipiosbrasileiros-2003

IBGE/GLÓRIA. Informações sobre Nossa Senhora da Glória via portal IBGE, disponível em: http://cod.ibge.gov.br/M3T . Acesso em: fev. 2012.

IOKOI, Zilda. Igreja e Camponeses: Teologia da libertação e movimentos sociais no campo Brasil e Peru, 1964- 1986. São Paulo: FAPESP, 1996. 
KATHYUSCIA, Claudia Bispo de Jesus. "As vozes da boca da mata: a experiência da extensão universitária nos assentamentos de reforma agrária no município de Nossa Senhora da Glória". Universidade Federal de Sergipe, São-Cristóvão, 2013 (monografia).

JULIÃO, Francisco. O que são as ligas camponesas. São Paulo: Brasiliense, 1962.

LEITE, Sergio et al. Impacto dos assentamentos: Um estudo sobre o meio rural brasileiro. São Paulo: Fundação Editora UNESP, Nead, 2004.

LOERA, N. R. A espiral das ocupações de terra. São Paulo: Polis, 2006.

MARTINS, José de Souza (Org.). Introdução crítica à sociologia rural. São Paulo: Hucitec, 1983.

. (Org.). Travessias: a vivência da reforma agrária nos assentamentos. Porto Alegre: Editora da UFRGS, 2003.

Os camponeses e a política no Brasil: as lutas sociais. Petrópolis- RJ, 1981.

MEDEIROS, Leonilde et al. Assentamentos rurais: uma visão multidisciplinar. São Paulo: UNESP, 1994.

MEDEIROS, Leonildes Servólos de. Movimentos sociais no campo, lutas por direitos e reforma agrária na segunda metade do século XX. In: CARTER, Miguel. Combatendo a desigualdade social: o MST e a reforma agrária no Brasil. São Paulo: Editora UNESP, 2010.

MORISSAWA, Mitsue. A história da luta pela terra e o MST. São Paulo: Expressão Popular, 2001.

MST. Atividades e atuações do MST em Sergipe: 30 anos 1984- 2014. Sergipe: MST; CFAC, 2014. 1 DVD.

. Cartilha "Orientação Políticas e Práticas para os Delegados do VI- Congresso". Brasília, fev. 2014.

. Movimento dos Trabalhadores Sem Terra. Disponível em: http://www.mst.org.br/

MST. Reforma Agrária Popular. In: . Cartilha "Orientação Políticas e Práticas para os Delegados do VI- Congresso" Brasília, fev. 2014.

. Subsídios para debate de temas estruturais da sociedade brasileira e os desafios para uma reforma agrária popular. Caderno de Debates № 01 - reparação para o VICongresso Nacional. Jun. 2013.

MST/SERGIPE. Movimento dos Trabalhadores Sem Terra- Sergipe. Disponível em: http://mstsergipe.blogspot.com.br/. Acesso em jun. 2014. 
NOBRE, Gismário Ferreira. Dilemas do movimento dos Trabalhadores Rurais sem Terra na relação Estado e sociedade: entre a autonomia e a institucionalização: o caso de Sergipe. Salvador: Universidade Federal da Bahia, 2008. (Tese de doutorado em Sociologia)

SANTOS, Janio; MENEZES, Sócrates; SOUZA, Suzane (org.) Novas configurações do espaço agrário nordestino: expansão do capital versus movimento e organizações sociais de luta pela terra e pelo trabalho. Vitória da Conquista: UNESB, 2010.

ROSSETO, Neuri; RIBEIRO, Fátima. A sociedade brasileira. In: MST. Subsídios para debate de temas estruturais da sociedade brasileira e os desafios para uma reforma agrária popular. Caderno de Debates № 01 - preparação para o VI- Congresso Nacional. Jun. 2013.

RIBEIRO, Ana; SANTANA, Marylane. A participação dos agricultores familiares nos conselhos municipais de desenvolvimento rural: um processo de construção. São Cristóvão: Universidade Federal de Sergipe, 2002. (Trabalho de conclusão de cursoServiço Social)

SOARES, Laura Tavares. O MST e a reforma agrária no governo Lula. In: SADER, Emir; BENJAMIN, César; GENTILI, Rafael. Governo Lula: decifrando o enigma. São Paulo: Viramundo, 2004.

STEDILE, João Pedro; FERNANDES, Bernardo Mançano. Brava gente: a trajetória do MST e a luta pela terra no Brasil. 2ª edição, São Paulo: Expressão Popular, coedição Fundação Perseu Abramo, 2012.

TURATTI. Maria Cecília Manzoli. Os filhos da lona preta: identidade e cotidiano em acampamentos do MST. São Paulo: Alameda, 2005.

WANDERLEY, Maria Nazareth Baudel. O mundo rural como um espaço de vida. Porto Alegre: Editora da UFRGS, 2009.

. "Morar e Trabalhar": o ideal camponês dos assentados de Pitanga. In: MARTINS, José de Souza (org.). travessias: a vivência da reforma agrária nos assentamentos. Porto Alegre: UFRGS, 2003, p. 203- 247.

Recebido em 30/04/2017

Aprovado em 04/01/2018 